\title{
EFFECTIVENESS OF TRAINING: THE CONCEPTUAL FRAMEWORK AND METHODOLOGICAL STRATEGY OF A LONGITUDINAL STUDY IN THE PORTUGUESE ARMED FORCES
}

\author{
Nuno Alberto Rodrigues Santos LOUREIRO ${ }^{1^{*}}$, Mariana Gaio ALVES ${ }^{2}$ \\ ${ }^{1}$ Military University Institute Research and Development Centre (CIDIUM), \\ Military University Institute, Lisbon, Portugal, Faculty of Sciences and Technology, \\ NOVA University of Lisbon, Lisbon, Portugal \\ ${ }^{2}$ Institute of Education, University of Lisbon, Lisbon, Portugal
}

\begin{abstract}
Considering that this research is still ongoing, this paper focuses on the presentation of the conceptual framework and its interconnection with the methodological strategy for the empirical study that aims to study the learning transfer to the workplace of professional military education in the context of the Portuguese Armed Forces. Factors related to the trainees' individual characteristics, the organisational context, the courses design, the organisational learning culture, the organisational commitment and the expectations of career development, as well as the relationships established between these factors and the intention to transfer, throughout the lifelong learning process, will be discussed. The empirical study will be carried out at three junctures - before the training, at the end of the training and three to six months after the training.
\end{abstract}

The study is conceptually based on Holton's Holistic HRD Research and Evaluation (1996), Ajzen's Theory of Planned Behaviour (1991), Watkins and Marsick's model of learning organisations (1993, 1996) and Meyer and Allen's (1991) concept of organisational commitment.

The study will be developed using a mixed strategy (quantitativelqualitative), applying a hypotheticaldeductive and inductive reasoning, in which a longitudinal research design with a transversal

* Corresponding author: nuno.a.loureiro@gmail.com

OPEN 2 Access (c) () $\fallingdotseq 2019$ N. Loureiro, M.G. Alves, published by War Studies University, Poland. This work is licensed under the Creative Commons Attribution-NonCommercial-NoDerivatives 4.0 License. 
component will be followed. The data collection for the empirical study will be done through a questionnaire, individual semi-structured interviews and discussion groups about the results.

Keywords: Adult Education, Training Transfer, Organisational Commitment, Organisational Learning Culture, Armed Forces

\section{Introduction}

This paper intends to present the conceptual framework of the investigation "Effectiveness of Training: A Longitudinal Study in the Portuguese Armed Forces" and its interconnection with the methodological strategy for the future related empirical studies. It will start by contextualising education and training in the Portuguese Armed Forces, referring to some of the main current concerns. The research conceptual framework will then be developed, referring to the theoretical support of the conceptual model and the objectives to achieving it. Furthermore, in the analysis model, its methodological development and the procedures and instruments to be used in each of the four phases of the research will be explained. Finally, the expected main contributions to knowledge and some of the ethical concerns of this work will be addressed.

As in most organisations, as in the Portuguese Armed Forces, the professional career education, designated as Professional Military Education (PME), is oriented to satisfying the organisational needs.

Created in 2015 (Ministério da Defesa Nacional 2015), the Military University Institute is the higher education institution for military studies, providing training and education to the officers of the Armed Forces and the National Republican Guard throughout their careers, enabling them to perform command and staff duties within their own branches, combined joint forces and within national or international institutions/organisations. The Military University Institute is integrated in the public higher education system, which implies its continued evaluation by the Portuguese Accreditation and Evaluation Agency for Higher Education (A3ES).

The effectiveness of training is a critical success factor for organisations, given the necessary investments and expected results. This issue is particularly relevant for the Armed Forces which have to reconcile reductions in the available budget with training their workforce to meet the challenges of a volatile, uncertain, complex and ambiguous 
world (VUCA) $)^{1}$, with the understanding that professional military education "helps establish the conditions for military success by creating the intellectual architecture to make military operations more effective" (Toronto 2015, p. 2). By establishing this effectiveness, to a large extent, in the effective transfer of training to the workplace, it is relevant to master the factors that influence it.

To achieve training effectiveness and efficiency in a military context, essential requirements need to be met, such as:

- Implementing an educational system linked with the various stages of development of people's careers;

- Selecting effective and efficient curricula that can contribute to people's on-the-job objectives and needs;

- Guaranteeing the education return of investment to the institution (results and means) and to the personal (motivation and performance), ensuring the alignment of collective and individual interests.

Therefore, the current challenges of PME, in view of its objectives, are:

- Ensuring curricular (re)alignment between requirements and needs and the creation of competencies for the fulfilment of the mission;

- Evaluating the effectiveness of the education process, especially with respect to behavioural changes and organisational results;

- Searching for a good cost / benefit ratio;

- Re-thinking the continuous career training in order to optimise it;

- The consolidation of an educational management model, guaranteeing effectiveness and efficiency through the internal and external validation of the training.

This is in line with current research which aims to study the transfer of training (PME) to the workplace in a military context. We will consider factors related to the trainees' individual characteristics, organisational context, training design, learning culture, organisational commitment and career development expectations, as well as the relationships established between these factors and the intention to transfer. The empirical study will be carried out at three junctures - before the training, at the end of the training, and three to six months after the training - and intends to enable an understanding of how this influence evolves throughout the process.

1 Concept introduced by U.S. Army War College to describe the multilateral world resulting from the end of the Cold War: Volatile, Uncertain, Complex and Ambiguous. 


\section{Literature Review}

Professional Military Education (PME) covers a wide range of activities, from professional training, competence development, and schooling of officers. Being progressive and sequential in a career, and being linked, many times to the civil academy, increases knowledge and develops the attributes of a leader to carry out current and future military missions. In fact, the PME develops throughout five perfectly defined career levels, ranging from the initial master's degree course at the Academies to the promotion course to flag officer, passing through the promotion course to captain, promotion course to senior officer and joint staff course (Orsi 2017).

It is also important to establish the difference between education and training in a military context. Normally, training is associated with the teaching and practice of a specific competence which prepares the military for systems operation, while the education provides a body of knowledge and the opportunity to develop critical thinking in dealing with highly complex operational environments and dynamics. "On one hand, the military as an organisation promotes critical thinking, learning, and adaptive leadership through education. On the other, it promotes authority, hegemony, and cultural tradition through training" (Gleiman and Zacharakis 2016, p. 88).

When it comes to measuring training effectiveness, Kirkpatrick's four-level model emerges immediately (Kirkpatrick 1975, 1996, Kirkpatrick and Kirkpatrick 2008, 2010, 2011, 2014, 2015) as the most used, essentially when related to the first two levels: reaction and learning. With regard to the third and fourth levels, behaviours and outcomes, few organisations implement them, perhaps because of their greater complexity and cost. And when we talk about behaviours and results, we talk about the effectiveness of the transfer of training to the workplace.

One of the most influential models for understanding and explaining the process of transfer of training was proposed by Baldwin and Ford (1988). According to these authors, the generalisation and maintenance of training content is directly influenced by three main factors:

- Trainees' characteristics, including their abilities, personality and motivation;

- The work environment through support and application opportunities;

- The retention of learning, which in turn is influenced by the design of the training that incorporates variables such as learning principles, sequence and content of the training. 
Complementing the work of Baldwin and Ford, Holton (1996) developed a holistic model, considering that the transfer of learning depends on:

- Secondary influences, such as personality traits, self-efficacy and professional attitudes;

- Motivation to learn and transfer;

- Social and organisational support for behavioural change;

- Skills for learning and course design.

The multidimensionality of the concept of transfer makes it possible to point out different and important aspects to be considered in the transfer analysis. In fact, the period after training, in which the worker returns to perform his or her function, is a critical factor to consolidate learning and have real effects on professional performance. Evidence that only a small percentage of the training results in a real transfer to the workplace has only recently begun to receive more attention as an essential aspect to discovering the success of the training, as well as studying the immediate reactions and the learning of the trainees. It is therefore necessary to analyse in what contexts the transfer of training occurs, as well as the factors that facilitate it or, on the contrary, make it difficult to demonstrate.

Holton and Bates (Holton et al. 2000, 2007, Bates 2004, Holton 2005, Velada et al. 2009, Bates et al. 2012, Hutchins et al. 2013, Alvelos et al. 2015, Banerjee et al. 2016), two of the most prolific researchers in the field of training transfer, consider that training evaluation policies, implemented in organisations, can drastically reduce the gap between organisational expectations and individuals' achievements. Being a multidimensional construct, the formative process incorporates motivational factors, accessibility, rewards and support, whose effectiveness can be measured through the quality and quantity of skills acquired, the transfer to the workplace and the results produced in the organisation. As a matter of fact, organisations invest very high amounts in the training of their employees, and they expect to extract from this investment the equivalent return on skills, knowledge, productivity, performance, attitudes and competitiveness, assuming the transfer of training as a strategic tool (Alnowaiser 2017).

This complex process of transfer of training constitutes a true system, which includes individual differences and perceptions, the training itself and the context in which it occurs (Bates et al., 2012).

Based on Holton's model (1996), the Learning Transfer System Inventory is a questionnaire designed to empirically assess the individual perceptions of the catalysts 
and barriers to transfer learning from vocational training (Bates et al., 2012, p. 550). It fills the gap in the evaluation of learning and the factors that influence and affect its transfer to the workplace. It is divided into four broad groups of factors, namely: the trainees' characteristics, the training design, the motivation and the work context characteristics. It is an instrument that HR practitioners have at their disposal and can use to assess potential problems prior to training, as part of the ongoing evaluation of established programmes, as a diagnostic tool to investigate training problems, to guide interventions for increasing the transfer, incorporating the transfer assessment into the performance evaluation of employees and to conduct training needs assessments ( Holton et al., 2000).

Meyer and Allen $(1991,1997)$ define organisational commitment as a psychological link between the employee and the organisation that makes voluntary abandonment unlikely. Understood in this way, this link can be a powerful tool for retaining talent in an increasingly competitive job market. Organisational commitment is explained by attitudes of belief and acceptance of the values of the organisation, intention to use their capabilities and devote their effort to the organisation, allied to an assumed willingness to remain in the organisation (affective commitment); by a link based on expected rewards or the costs associated with abandonment (calculating commitment); when a relationship of subordination and authority is established (sociological commitment); by pressures related to normative behaviours (normative commitment) (Dirani and Kuchinke 2011).

Although it was initially approached as a one-dimensional construct (Mowday et al. 1978), studies point to its multidimensionality (Meyer et al. 1993). This multidimensionality better explains the understanding of individual behaviour in a given organisational context. Thus, organisational commitment along with material compensation and support from supervisors is one of the strongest predictors of organisational performance (Velada 2007).

Organisational culture is an important variable in explaining the transfer of training (Velada 2007). More specifically, this relationship is analysed in terms of the existence or not, in the organisation, of a culture characterised by the promotion of the continuous learning of its collaborators.

Tracey et al. (1995) define the culture of continuous learning as the sharing of perceptions and expectations of all members of the organisation that learning is essential for them 
and associated with their daily work. In this sense, for these authors, the culture of continuous learning can be considered as a specific part of the general organisational culture, considering that the organisational culture, as Schein defined it (1985), is a system of values and beliefs shared by the members of an organisation.

The organisational learning culture (OLC) enhances knowledge acquisition practices and the transfer of learning (Yang et al. 2004) by developing consensus on the value of knowledge and the use of that knowledge to further the goals of organisations. OLC has a positive impact on performance variables such as knowledge and financial performance and is essential to maintaining competitive advantage (Banerjee et al. 2016).

Through OLC's influence, employees share a common vision and information channels and are encouraged to foster interactive learning by creating and sharing knowledge and values. These are the main features that differentiate OLC from other organisational cultures (Li and Liu 2014).

Culture and the learning climate facilitate the transfer of knowledge through informal and non-formal channels, increasingly based on the exchange of experiences, thus increasing peer support, essential for organisational performance (Marsick and Watkins 2003).

Yang et al. point out that OLC has a positive impact on improving organisational commitment (1978) including best model-data fit among alternative measurement models, nomological network among dimensions of the learning organization, and organizational performance outcomes. Acceptable reliability estimates were obtained for the seven proposed dimensions. Consequently, the instrument, Dimensions of the Learning Organization Questionnaire, was recommended for use in organizational studies. The concept of the learning organization has received increasing attention in the field of organizational studies, yet little is known about how to measure it. Despite growing attention to the learning organization, the lack of a theo-retically derived measure of the construct has deterred substantive research in this area (Tsang 1997). The Marsick and Watkins model (2003) identifies seven actions that a learning organisation should practice: providing continuing education opportunities, promoting dialogue, encouraging work and collaborative learning, establishing knowledge sharing systems, linking organisation to context, and seeking leaders involved with the process. The learning organisation is one in which organisational learning is based on teamwork, collaboration, creativity and knowledge of processes with collective value and meaning 
(Joo 2010) 43\% of the variance in organizational commitment was explained by organizational learning culture and LMX quality. About $40 \%$ of the variance in turnover intention was explained by organizational commitment. Thus, perceived organizational learning culture and LMX quality (antecedents).

Another two concepts that are intended to be analysed are career exploration, which is a process of life-long search for information relevant to career progression, triggered particularly during transitions, as it allows us to face them (Stumpf et al. 1982, Zikic and Klehe 2006); and career planning, defined as the development of future careers, pursuing career goals (Gould 1979, Zikic and Klehe 2006).

According to the Theory of Planned Behaviour, human behaviour is guided by beliefs about the likely outcome of that behaviour and its evaluation (behavioural beliefs that produce a favourable or unfavourable attitude towards a behaviour), beliefs about the expectations of others, and motivation to materialise those expectations (normative beliefs that result in perceived social pressure or subjective norm), and beliefs about the presence and power of factors that may facilitate or prevent behaviour (control beliefs that offer perceived behavioural control). These three combined dimensions give rise to a behavioural intention, which will be as strong as the behavioural, normative, and controlling beliefs in carrying out the behaviour in question. The intention is thus assumed to be the immediate antecedent of the behaviour (Ajzen 1985, 1991, 2005) human behavior is guided by three kinds of considerations: beliefs about the likely outcomes of the behavior and the evaluations of these outcomes (behavioral beliefs).

In particular, the intention to transfer is indicated as a precursor to any initiatives related to the transfer of training to the workplace. Machin and Fogarty (1998) say that it is a commitment to act in a certain way, whenever certain conditions are met. Implementation intentions were considered instrumental in making the individual more aware of environmental aspects more relevant to the achievement of their goals. If the trainee does not intend to transfer, it is unlikely that any transfer will occur (Machin and Fogarty 2003, 2008). 


\section{Method}

The study is supported by Holton's (1996) Holistic HRD Research and Evaluation model, in Ajzen's Theory of Planned Behaviour (Ajzen 1985), in the model of the learning organisations of Yang, Watkins and Marsick (1978) and in the concept of organisational commitment by Meyer and Allen (1991). It will be developed using a mixed strategy (quantitative / qualitative) (Creswell 2013), applying a hypotheticaldeductive (Quivy and Campenhoudt 2008) and inductive reasoning (Santos and Lima 2016), where a research design is of a longitudinal design with a transversal component (Bryman 1988).

The object of the research is PME, based on the identification and study of the factors that affect the transfer of learning to the workplace, throughout the career, in the different stages of the learning process, in the military organisational context.

The aim of the research is: (1) to better understand the process of transferring learning to the workplace, associated with career military education and (2) to identify, analyse, describe and explain the factors that impact the transfer of learning to the workplace, associated with career military education.

The specific objectives are as follows: (1) define and validate a research and diagnostic tool for the process of transferring learning to the workplace, associated with career military education; (2) identify and analyse the factors that affect the intention to transfer learning to the workplace at different stages of the learning process; and (3) evaluate the moderating effect of the design of training and the transfer climate in order to transfer learning to the workplace.

Based on the literature review, an analysis model for this research was developed with the three junctures identified (Figure 1), before the course, after the course and six months after the course. 


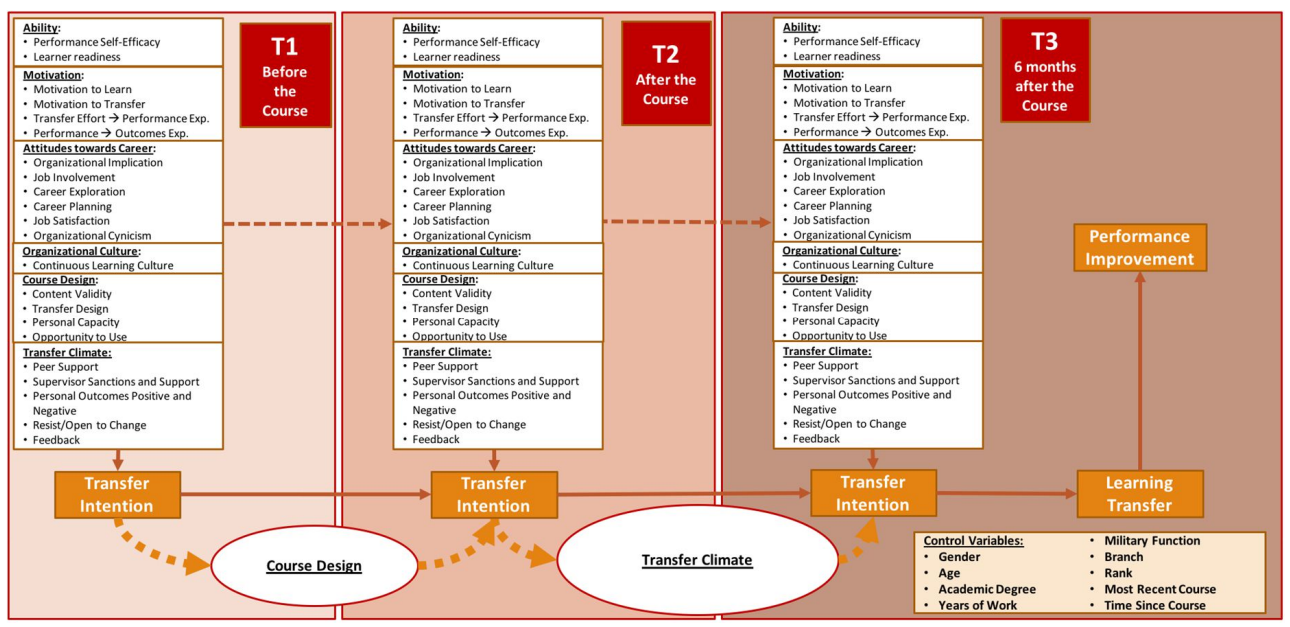

Fig. 1. Analysis model

Considering that the improvement of organisational performance is strongly related to the effectiveness of training and this, in turn, with the transfer of training to the workplace, it is assessed that the individual characteristics and motivations of the trainees and the factors of organisational context which influence the formative process, will have an impact on this transfer through learning. It is also conceptualised that this impact will vary throughout the training process, due to training design and the work environment subsequent to the training.

Based on the proposed conceptual model, it is hypothesised that individual factors, work environment, training design, organisational learning culture, organisational commitment and career planning and exploration influence the intention to transfer and have a significant effect on training outcome and performance improvement.

It is expected that the analysed factors influence directly and in a positive way the intention to transfer, in all of the moments observed, although with different weights. With regard to variation throughout the training process, several factors may affect its evolution in a different way, as well as the impact on the intention to transfer. Knowing these variations is one of the objectives of this study; however, it is assumed from the outset that the frequency of training and the organisational climate will increase the intention to transfer, and the reason why the following hypotheses are posed:

H1 - The factors that affect the transfer of training, before, at the end and six months after the end of the training, are directly and positively related to the Intention to Transfer. 
$\mathrm{H} 2$ - From the beginning to six months after the end of the training, the influence of the factors that impact on the transfer of the training is increasing, inducing the increase of the Intention to Transfer in the same period.

Likewise, because the organisational learning culture, organisational commitment and career planning and exploration may motivate an increase in the intention to transfer, a significant influence will be expected, which will increase over the period under review. The following hypotheses are put forward:

H3 - Organisational learning culture, organisational commitment and career planning and exploration, before, at the end and six months after the end of training, are directly and positively related to the Intention to Transfer.

H4 - Between the beginning and six months after the end of training, the influence of organisational learning culture, organisational commitment, and career planning and exploration is increasing, inducing the increase of the Intention to Transfer in the same period.

Assuming that the training actions, in terms of their curricular content, are aligned with the needs of the individual and the organisation, and are designed in an appealing way for the trainees, it is expected that their frequency will have a positive impact on the intention to transfer, then the hypothesis is:

H5 - The design of training enhances the effects of the organisational learning culture, organisational commitment and career planning and exploration of the individual, increasing the intention to transfer, at the end of training.

With regard to the organisational context it is also considered that there will be conditions in the workplace that will potentiate the effects of organisational learning culture, organisational commitment and planning and career exploration of the military, increasing the intention to transfer, six months after training. The hypothesis is then:

H6 - The organisational context enhances the effects of organisational learning culture, organisational commitment, and career planning and exploration, increasing the intention to transfer, six months after training.

One of the reasons for the study of the transfer of training to the workplace is related to the proven relationship with the effectiveness of training in terms of impact on organisational results. In this way, it is expected that they directly and positively 
influence the improvement of individual and organisational performance. The working hypothesis will be:

H7 - The factors that impact the transfer of training, before, at the end and six months after the end of training, are directly and positively related to the improvement of individual and organisational performance.

What is the role of intent to transfer in improving performance? We try to answer this question by putting the following hypothesis at the start:

H8 - The intention to transfer empowers the effects of individual factors, work environment and training design, organisational learning culture, organisational commitment and career planning and exploration of the individual, increasing individual and organisational performance improvement.

The development of the research will take place in four phases, each incorporating an empirical study.

\section{Phase 1}

The construction and validation of the instrument of identification and measurement of the factors that impact the intention of transferring learning to the workplace will be carried out, based on the following scales:

- Learning Transfer System Inventory, LTSI Version 4 (Bates, Holton and Hatala, 2012).

- Organisational Commitment Questionnaire, OCQ (Meyer and Allen, 1991).

- Dimensions of Learning Organisation Questionnaire, DLOQ, (Watkins and Marsick, 1993, 2003; Yang, 2003).

- Intention to Transfer Scale (Machin and Fogarty, 2003).

Additional ad-hoc items will be added to investigate specific factors related to the military context.

In the adaptation of the Military Learning Transfer Factors questionnaire, a methodology based on translation / retroversion with the participation of bilingual military personnel will be used, in the subjective and objective evaluation developed by the investigators, 
and in a pre-test submitted to a sample of convenience of 30 participants (Dimitrova 2010, Bates 2018).

The questionnaire will then be submitted to a population of officers who have already participated in an ESPM course, with reliability being measured through the internal consistency analysis (Cronbach's Alpha) and validation by the Structural Equation Modelling (SEM) method. Factorial Confirmatory Analysis (AFC) (Maroco 2018).

\section{Phase 2}

A comparative study of the factors that affect the intention to transfer, throughout the learning process, from the beginning of the training to six months after returning to the workplace. This study will have as objectives:

- Measure the individual and organisational factors that directly influence the intention to transfer learning to the workplace in the military context before the course, right after the course and six months after the course;

- Measure the variance of individual and organisational factors that directly influence the intention to transfer learning to the workplace in the military context before the course, right after the course and six months after the course;

- Measure the variance of individual and organisational factors that directly influence the intention to transfer learning to the workplace in the military context before the course, right after the course and six months after the course, and its predictive capacity regarding the transfer of learning and performance improvement.

The Military Learning Transfer Factors questionnaire will be submitted to officers participating in PME courses in 2018 and 2019.

The results will be analysed through Factorial Confirmatory Analysis (FCA), Correlation Analysis, Analysis of Variance (ANOVA) and means, standard deviation, minimum and maximum estimates (Maroco 2018). 


\section{Phase 3}

This study will evaluate the mediating role of training design and the transfer climate in the relationship between the factors and the intention to transfer learning to the work place, measured before the course, after the course and six months after the course.

The Military Learning Transfer Factors questionnaire will be submitted to officers participating in PME courses in 2018 and 2019.

The results will be analysed through Factorial Confirmatory Analysis (AFC) and Structural Equations Modelling (SEM) (Maroco 2018).

\section{Phase 4}

It will be an exploratory study of other factors that influence the transference of learning to the workplace, throughout the learning process.

Although phases 2 and 3 are quite exhaustive in the number of variables analysed, with an impact on the intention to transfer to the work place, in the military context, in stage 4 some trainees are chosen from the beginning of the course until six months after the course, collecting periodically, through unstructured interviews and focus groups, their opinions and perceptions about barriers and / or catalysts of the learning process and later intention to transfer to the workplace.

To this end, it is intended to follow up on 10 officers, selected from the courses under analysis, periodically conducting unstructured interviews and discussions in the Focal Group on learning transfer factors.

On the information thus collected, the necessary content analysis (Bardin 2010) will be done according to the general inductive approach (Creswell 2013).

Finally, some of the ethical issues that are of concern to this research are: (1) authors will be requested to use the scales that will serve as the basis for the preparation of the data collection instruments; (2) higher military authorisation will be requested to develop field work in the Armed Forces Branches; (3) anonymity of participants and data confidentiality in the collection, processing and presentation of results (identification 
codes for longitudinal monitoring will be ensured); and (4) data integrity will be ensured during statistical treatment and content analysis.

\section{Conclusion}

Taking into account that this research is still ongoing, this article presented the conceptual framework and its interconnection with the methodological strategy for the empirical study.

As previously mentioned, the study is based on Holton's (1996) Holistic HRD Research and Evaluation model, in Ajzen's Theory of Planned Behaviour (Ajzen 1985), in the model of the learning organisations of Yang, Watkins and Marsick (1978) and in the concept of organisational commitment by Meyer and Allen (1991), and will be developed using a mixed strategy (quantitative / qualitative) (Creswell, 2013), applying a hypothetical-deductive (Quivy and Campenhoudt, 2008) and inductive reasoning, where it will be followed by a longitudinally delineated survey design with a crosssectional component (Bryman, 1988).

Its general objectives are to better understand, in the context of PME, the process of transferring learning to the workplace, and to identify, analyse, describe and explain the factors that impact on this transfer of learning to the workplace.

It is considered that this research will be relevant, contribute and add value to the body of knowledge related to transfer of training, deepening the relationships between the factors that affect and condition this transference, acting as a useful measure to anticipate or predict how the trainees transfer new skills to the work effectively.

The collection and analysis of the results of the application of the Learning Transfer System Inventory (LTSI), in its fourth version (Bates, Holton and Hatala 2012), longitudinally, before training, at the end of training and six months after training will contribute to the study of the effects of factors influencing the transfer of training over time, for which there is little research.

Another contribution to the scientific community and human resource management practitioners will be the analysis of the relationships between the organisational learning 
culture, organisational commitment and the planning and exploration of the individual's career and the intention to transfer.

LTSI is an instrument that has been used in several contexts in the trade, industry, agriculture and services sectors (Bates et al. 2012; Holton 2005; Holton, Bates and Ruona 2000), in the areas of health, education, sports, banking, private and public administration, including security forces; however, there is little information on its application in the military context. Also in this respect, given the specific nature of continuing military training, this study will be of considerable value to military personnel responsible for human resources, particularly those directly involved in the planning, execution and evaluation of training,

In this particular way for the Armed Forces, this study adds an integrated form of evaluation of the effectiveness of career education, not only empirically identifying the factors that impact on training, but also providing the validated and tested instruments, essential for accomplishing the evaluation and enabling timely interventions in the pursuit of continuous improvement of training standards.

It is considered that this research is extremely relevant for the scientific community that studies these phenomena, and also for the MUI and for the Portuguese Armed Forces, since in providing for quality education of the military, it will leverage an improvement in the fulfilment of the mission to guarantee the defence of the Nation.

\section{References}

Ajzen, I., 1985. Behavioral Interventions Based on the Theory of Planned Behavior. Action Control, 11-39.

Ajzen, I., 1991. The theory of planned behavior. Organizational Behavior and Human Decision Processes, 50 (2), 179-211.

Ajzen, I., 2005. Attitudes, Personality and Behavior. 2nd ed.

Alnowaiser, A., 2017. The impact of work environment, individual characteristics, training design and motivation on training transfer to the work: the case of Saudi Arabian Public Security Organisation. University of Westminster.

Alvelos, R., Ferreira, A.I., and Bates, R., 2015. The mediating role of social support in the evaluation of training effectiveness. European Journal of Training and Development, 39 (6), 484-503.

Baldwin, T.Ti.T. and Ford, J.K., 1988. Transfer of Training: a Review and Directions for Future Research. Personnel Psychology, 41 (1), 63-105. 
Banerjee, P., Gupta, R., and Bates, R., 2016. Influence of Organizational Learning Culture on Knowledge Worker's Motivation to Transfer Training: Testing Moderating Effects of Learning Transfer Climate. Current Psychology, 1-12.

Bardin, L., 2010. Análise de conteúdo. Lisboa (Portugal): Ediçóes, 70.

Bates, R., 2004. A Critical Analysis of Evaluation Practice: the Kirkpatrick Model and the Principle of Beneficence. Evaluation and Program Planning, (27), 341-347.

Bates, R., 2018. Translation Process for Surveys: From English to a Target Language.

Bates, R., Holton, E.F., and Hatala, J.P., 2012. A revised learning transfer system inventory: Factorial replication and validation. Human Resource Development International, 15 (5), 549-569.

Bryman, A., 1988. Quantity and Quality in Social Research. New York: Taylor \& Francis e-Library. Creswell, J., 2013. Research Design: Qualitative, quantitative, and mixed methods approaches. 2nd ed. Dimitrova, B.E., 2010. Translation process. In: Y. Gambier and L. van Doorslaer, eds. Handbook of Translation Studies. 406-411.

Dirani, K.M. and Kuchinke, K.P., 2011. Job satisfaction and organizational commitment: Validating the arabic satisfaction and commitment questionnaire (ASCQ), testing the correlations, and investigating the effects of demographic variables in the lebanese banking sector. International Journal of Human Resource Management, 22 (5), 1180-1202.

Gleiman, A. and Zacharakis, J., 2016. Continuing Professional Education in the Military. NEW DIRECTIONS FOR ADULT AND CONTINUING EDUCATION, Fall (151), 81-90.

Gould, S., 1979. Characteristics of Career Planners in Upwardly Mobile Occupations. Academy of Management Journal, 22 (3), 539-550.

Holton, E.F., 1996. The flawed four-level evaluation model. Human Resource Development Quarterly; Spring, 7 (1).

Holton, E.F., 2005. Holton's Evaluation Model: New Evidence and Construct Elaborations. Advances in Developing Human Resources, 7 (1), 37-54.

Holton, E.F., Bates, R.A., Bookter, A.I., and Yamkovenko, V.B., 2007. Convergent and divergent validity of the learning transfer system inventory. Human Resource Development Quarterly, 18 (3), 385-419.

Holton, E.F., Bates, R.A., and Ruona, W.E.A., 2000. Development of a generalized learning transfer system inventory. Human Resource Development Quarterly, 11 (4), 333-360.

Hutchins, H.M., Nimon, K., Bates, R., and Holton, E., 2013. Can the LTSI predict transfer performance? Testing intent to transfer as a proximal transfer of training outcome. International Journal of Selection and Assessment, 21 (3), 251-263.

Joo, B.-K., 2010. Organizational commitment for knowledge workers: The roles of perceived organizational learning culture, leader-member exchange quality, and turnover intention. Human Resource Development Quarterly, 21 (1), 69-85.

Kirkpatrick, B.J.D. and Kirkpatrick, W.K., 2010. ROE’s Rising Star: Why Return of Expectations are getting so much attention [online]. Kirkpatrick Partners. Available from: https://www. kirkpatrickpartners.com/Resources/ROEs-Rising-Star [Accessed 13 Jan 2018].

Kirkpatrick, D., 1996. Great ideas revisited: Revisiting Kirkpatrick's Four-Level Model. Training \& Development.

Kirkpatrick, D. and Kirkpatrick, J., 2008. Evaluating Training Programs - The Four Level Model. 3rd ed. Berrett Koehler. 
Kirkpatrick, D.L., 1975. Evaluating training programs. Tata McGraw-Hill Education.

Kirkpatrick, J. and Kirkpatrick, W., 2015. An Introduction to the New World Kirkpatrick Model.

Kirkpatrick, J. and Kirkpatrick, W.K., 2014. The Kirkpatrick four levels: A fresh look after 55 years 1959-2014.

Kirkpatrick, J.D. and Kirkpatrick, W.K., 2011. Creating ROE: the end is the beginning [online]. Kirkpatrick Partners. Available from: https://www.kirkpatrickpartners.com/Portals/0/ Storage/Newsletter articles/Creating ROE ASTD 11 11.pdf?ver=2011-11-02-142832-000 [Accessed 13 Jan 2018].

Li, F. and Liu, P., 2014. Review of Organizational Learning Culture from the Perspective of Selfdependent Innovation. JOURNAL OF CHINESE ECONOMICS, 2 (1), 53-61.

Machin, M.A. and Fogarty, G.J., 1998. Assessing the antecedents of transfer intentions in a training context. International Journal of Training and Development, 8 (3), 222-236.

Machin, M.A. and Fogarty, G.J., 2003. Perceptions of training-related factors and personal variables as predictors of transfer implementation intentions. Journal of Business and Psychology, 18 (1), 51-71.

Machin, M.A. and Fogarty, G.J., 2008. The Effects of Self-Efficacy, Motivation to Transfer, and Situational Constraints on Transfer Intentions and Transfer of Training Organisational psychology View project Psychological assessment View project. Performance Improvement Quarterly, 10 (2), 98-115.

Maroco, J., 2018. Análise Estatística com Utilização do SPSS. Pêro Pinheiro.

Marsick, V.J. and Watkins, K.E., 2003. Demonstrating the Value of an Organization's Learning Culture: The Dimensions of the Learning Organization Questionnaire. Advances in Developing Human Resources, 5 (2), 132-151.

Meyer, J.P. and Allen, N.J., 1991. A three-component conceptualization of organizational commitment. Human Resource Management Review, 1 (1), 61-89.

Meyer, J.P. and Allen, N.J., 1997. Commitment in the workplace: Theory, Research, and Application. Human Resource Development Quarterly.

Meyer, J.P., Allen, N.J., and Smith, C.A., 1993. Commitment to Organizations and Occupations: Extension and Test of a Three-Component Conceptualization. Journal of Applied Psychology, 78 (4), 538-551.

Ministério da Defesa Nacional, 2015. Estatuto do Instituto Universitário Militar (Decreto-Lei n. ${ }^{\circ}$ 249/2015 de 28 de outubro). Lisboa: Diário da República, 9298-9311.

Mowday, R.T., Steers, R.M., and Porter, L.W., 1978. The Measurement of Organizational Commitment. Eugene, Oregon.

Orsi, D., 2017. Professional Military Education and Broadening Assignments: A Model for the Future. Joint Force Quarterly, (86), 41-49.

Quivy, R., Campenhoudt, L., 2008. Manual de Investigação em Ciências Sociais. 5a Edição. Trajetos. Lisboa: Gradiva.

Santos, L. and Lima, J., 2016. Orientaçôes metodológicas para a elaboração de trabalhos de investigação. Cadernos do IESM. Lisboa.

Schein, E.H., 1985. Organizational Culture \& Leadership.

Stumpf, S.A., Colarelli, S.M., and Hartman, K., 1982. The Career Exploration Survey: A Summary of its Dimensionality, Reliability, and Validity. Psychological Reports, 51 (1), $117-118$. 
Toronto, N.W., 2015. Does Military Education Matter? [online]. E-International Relations. Available from: http://www.e-ir.info/2015/05/26/does-military-education-matter/.

Tracey, J.B., Tannenbaum, S.I., and Kavanagh, M.J., 1995. The Scholarly Commons Applying Trained Skills on the Job: The Importance of the Work Environment Part of the Hospitality Administration and Management Commons.

Velada, A.R.R., 2007. Avaliação da eficácia da formação profissional: Factores que afectam a transferência da formação para o local de trabalho. Instituto Superior de Ciências do Trabalho e da Empresa.

Velada, R., Caetano, A., Bates, R., and Holton, E., 2009. Learning transfer - validation of the learning transfer system inventory in Portugal. Journal of European Industrial Training, 33 (7), 635-656.

Yang, B., Watkins, K.E., and Marsick, V.J., 1978. The Construct of the Learning Organization: Dimensions, Measurement, and Validation. Brown \& Duguid Fiol \& Lyles Isaacs \& Senge.

Yang, B., Watkins, K.E., and Marsick, V.J., 2004. The construct of the learning organization: Dimensions, measurement, and validation. Human Resource Development Quarterly, 15 (1), $31-55$.

Zikic, J. and Klehe, U.-C., 2006. Job loss as a blessing in disguise: The role of career exploration and career planning in predicting reemployment quality. Journal of Vocational Behavior, 69 (3), 391-409.

\section{Authors:}

Nuno Alberto Rodrigues Santos Loureiro, Major

Military University Institute Research and Development Centre (CIDIUM), Military University Institute, Faculty of Sciences and Technology, NOVA University of Lisbon, Lisbon, Portugal

https://orcid.org/0000-0003-3219-5327

Mariana Gaio Alves, $\mathrm{PhD}$

Institute of Education, University of Lisbon, Lisbon, Portugal 
